\title{
Colonização e biologia reprodutiva de mamangavas (Xylocopa frontalis) em um modelo de ninho racional
}

\author{
Colonization and reproductive biology of carpenter bees (Xylocopa frontalis) in a model of \\ rational nesting box
}

\author{
José Hugo de Oliveira Filho ${ }^{1}$ Breno Magalhães Freitas ${ }^{2,3}$
}

RESUMO

\begin{abstract}
As mamangavas (Xylocopa spp.) são importantes polinizadores, mas o seu criatório para introdução em áreas agrícolas tem sido dificultado pelo hábito de nidificação dessas abelhas. Propostas de ninhos racionais, que possibilitem a observação do seu interior, manejo e transporte para os pomares, não têm sido bem aceitas pelas abelhas. O presente trabalho testou a colonização e biologia reprodutiva das mamangavas em um modelo sugerido por FREITAS \& OLIVEIRA (2001). O resultado mostrou colonização por $\boldsymbol{X}$. frontalis em taxas entre 18,75 e $52,22 \%$, com 3,0 a 4,7 ninhos povoados por caixa. A arquitetura dos ninhos construidos foi semelhante ao observado em ninhos silvestres e o ciclo de ovo a adulto levou, em média, 45,58 dias. A relação macholfêmea das crias foi de 0,60:1,00. Conclui-se que o modelo de caixa racional testado apresenta boa aceitação por $\boldsymbol{X}$. frontalis $e$ não afeta a biologia reprodutiva dessa abelha.
\end{abstract}

Palavras-chave: mamangava, criatório racional, polinização, manejo de abelhas.

\section{ABSTRACT}

Carpenter bees (Xylocopa spp.) are important pollinators, but rearing them for introduction in agricultural areas has been difficult because of their nesting behavior. Models of rational nesting boxes, which allow observing their interior, manipulating the nests and transporting them to the orchards, have not been accepted by the bees. The present work tested colonization and reproductive biology of carpenter bees in a model of nesting box suggested by FREITAS \& OLIVEIRA (2001). Results showed 18.75 to $52.22 \%$ colonization by $\boldsymbol{X}$. frontalis, with 3.0 to 4.7 nests founded per box. Architecture of the nests built in the rational rearing boxes was similar to that observed in wild nests, and the cycle from egg to adult took an average of 45.58 days. The offspring ratio male/female was $0.60: 1.00$. It is concluded that the model of rational nesting box tested is well accepted by $\boldsymbol{X}$. frontalis and does not affect negatively the reproductive biology of this bee species.

Key words: carpenter bee, rational rearing, pollination, bee management.

\section{INTRODUÇÃO}

As mamangavas (Xylocopa spp.) são abelhas de porte avantajado que desempenham importante papel polinizador em diversas espécies vegetais de flores grandes, sejam elas silvestres como a castanheira-do-Pará (Bertholletia excelsa Humb \& Bonpl.) ou cultivadas como o maracujá-amarelo (Passiflora edulis Sims. f. flavicarpa Deg.) (CORBET \& WILLMER, 1980).

Estas abelhas nidificam escavando galerias em troncos de árvores mortas, galhos ou qualquer tecido vegetal já relativamente seco, sem fendas ou rachaduras (CAMILLO \& GARÓFALO, 1982; CAMILLO et al., 1986). Algumas espécies também podem nidificar em tecidos vegetais vivos (HURD, 1978). Tal comportamento de nidificação tem criado dificuldades para o uso das mamangavas como agentes

${ }^{1}$ Engenheiro Agrônomo, MSc.

${ }^{2}$ Engenheiro Agrônomo, PhD, Professor da Universidade Federal do Ceará, (UFC). E-mail:freitas@ufc.br. Autor para correspondência.

${ }^{3}$ Departamento de Zootecnia, UFC, CP 12168 Campus do Pici, 60021-970, Fortaleza-CE. 
polinizadores em áreas agrícolas, uma vez que não permite o manejo racional dos ninhos.

Porém, há uma grande necessidade de estudos que venham a possibilitar a criação artificial das mamangavas, fornecendo aos produtores agrícolas, tanto os insetos quanto informações sobre o manejo adequado (RUGGIERO, 2000). Dessa forma, tentativas têm sido feitas visando criar mamangavas para introdução em áreas cultivadas. Ninhos-armadilhas confeccionados em gomos de bambu (Bambusa sp.) ou vigotas de Pinus sp. têm sido usados para criar mamangavas com a finalidade de polinização em pomares de maracujá (CAMILLO, 1998; 2000). Propostas de formas de criação de mamangavas que permitam o manejo das abelhas foram feitas por MARDAN et al. (1994), que sugeriu o uso de blocos retangulares de madeira mantidos lado a lado. Esses, uma vez colonizados pelas mamangavas, poderiam ser remanejados da maneira mais conveniente ao criador. MARDAN (1995) propôs a colocação de blocos de madeira montados em molduras dentro de caixas retangulares para que funcionassem como uma colméia. FREITAS \& OLIVEIRA FILHO (2001) apresentaram um modelo de ninho para o criatório de mamangavas que se assemelha à colméia Langstroth e que permite manejar racionalmente essas abelhas para serviços de polinização.

O presente trabalho testou a aceitação, por parte das mamangavas, do ninho descrito por FREITAS \& OLIVEIRA FILHO (2001) e estudou os hábitos de nidificação e reprodução dessa abelha no referido ninho, comparando-os ao observado na natureza.

\section{MATERIAL E MÉTODOS}

A pesquisa foi conduzida nos municípios de Fortaleza e São Luís do Curú, ambos no Estado do Ceará, utilizando-se o modelo de ninho racional para mamangavas descrito por FREITAS \& OLIVEIRA FILHO (2001). Trata-se basicamente de uma colméia padrão Langstroth usada na criação de Apis mellifera, cujos quadros foram adaptados para nidificação de Xylocopa spp., de forma que cada um constitui um ninho independente (Figura 1). Devido à espessura dos quadros, cada caixa pode comportar nove ninhos de mamangava.

O quadro ou ninho verdadeiro é composto por uma barra superior que dá sustentação à tábua de madeira morta e seca que serve de substrato para a nidificação de Xylocopa. O substrato é protegido em cada lado por uma lâmina de vidro, cujas funções são delimitar o espaço lateral para construção das galerias e permitir a visualização da família. O ninho é completado por uma barra inferior que dá sustentação e mobilidade às lâminas de vidro, e serve de encaixe para a cunha de madeira que tem a função de entrada do ninho, conforme apresentado na figura 1 .

\section{Povoamento espontâneo dos ninhos racionais por mamangavas.}

Os dados foram coletados de abril a dezembro de 1999 em Fortaleza e, em São Luís do Curú, as mesmas informações foram obtidas entre abril e dezembro de 2000.

Em Fortaleza, trinta caixas racionais para mamangavas foram instaladas a $2 \mathrm{~m}$ de altura no galpão do apiário da Universidade Federal do Ceará. Simultaneamente, dez troncos de árvores mortas contendo diversos ninhos silvestres de mamangavas foram colocados de forma intercalada entre as caixas racionais. A partir de então, a saída de fêmeas jovens desses ninhos em busca por novos locais para nidificação e o povoamento das caixas racionais foi monitorado. Em relação às caixas racionais, coletaramse informações especialmente a respeito do comportamento de abordagem, aceitação e taxa de sucesso de nidificação.

Nas observações conduzidas a campo, em São Luís do Curú, utilizaram-se três propriedades nas regiões distritais do referido município, todas contendo no mínimo 1ha cultivado com o maracujá-amarelo. Nessa fase do experimento, 16 caixas racionais foram alocadas a campo, sendo que uma fazenda recebeu seis e, as demais, cinco caixas cada uma.

As caixas foram instaladas de forma aleatória dentro do plantio, sobre mourões com altura de $2,5 \mathrm{~m}$, fixados ao solo, ficando posicionadas acima da altura do segundo arame de sustentação da espaldeira do pomar. Não houve introdução de ninhos silvestres povoados com mamangavas próximos às caixas, como foi feito em Fortaleza. A partir da instalação, até o fim do experimento de campo, foram feitas observações diárias nas caixas acompanhando o povoamento dos ninhos para obter informações que permitissem determinar a taxa de aceitação e nidificação.

\section{Biologia reprodutiva das mamangavas nidificando nas caixas racionais.}

Essa etapa foi conduzida tanto em Fortaleza quanto em São Luís do Curú, a partir do experimento de nidificação descrito anteriormente. Dessa forma, após a confirmação da ocupação de cada ninho e coleta dos dados referentes ao seu povoamento e à espécie de Xylocopa que o fundou, fazia-se o registro da nidificação e se passava a acompanhar diariamente a família, coletando dados sobre o período de 


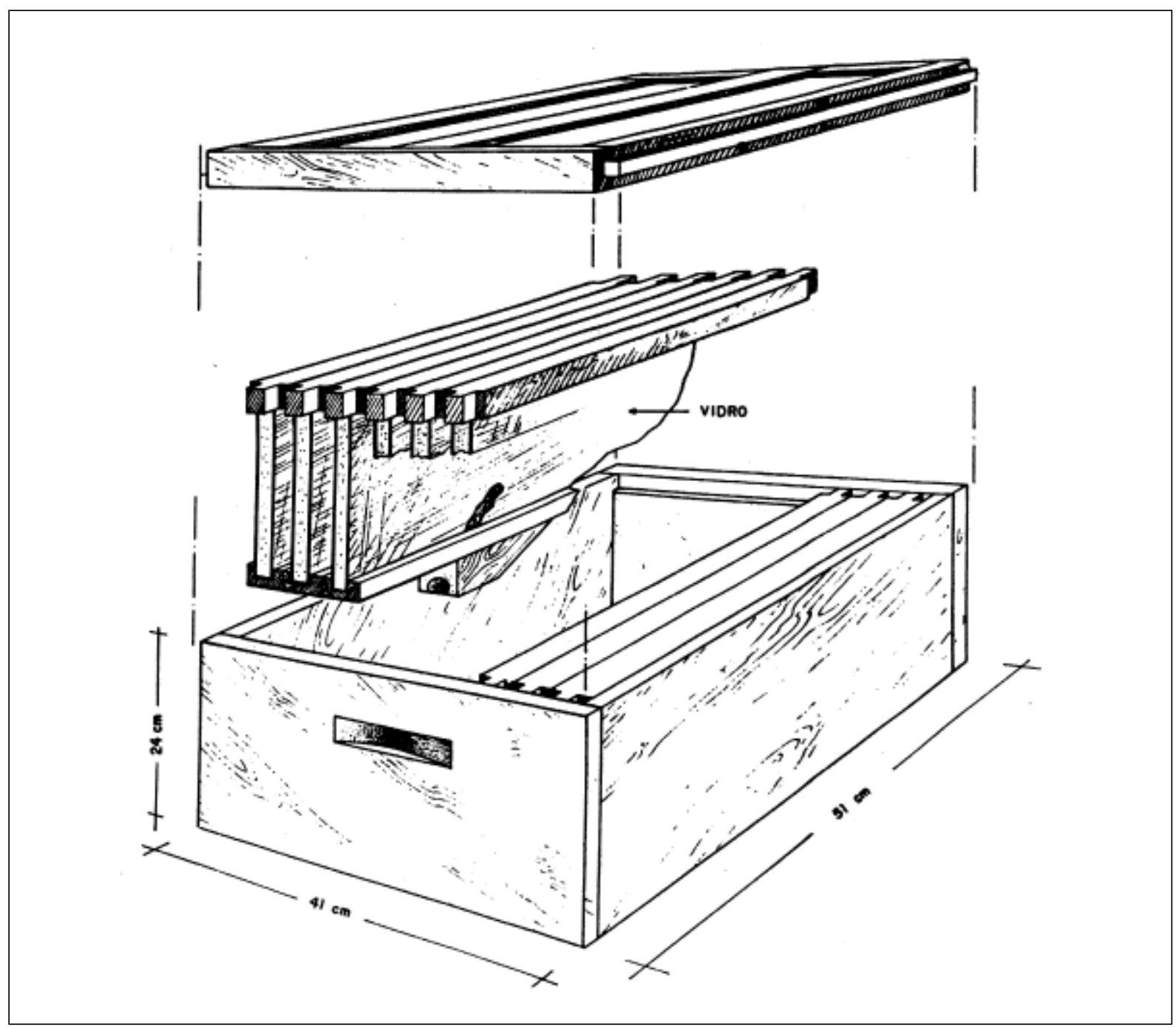

Figura 1 - Modelo de ninho racional para mamangavas, com destaque para os quadros móveis.

desenvolvimento, relação entre machos e fêmeas produzidos nos ninhos povoados, arquitetura e dimensões dos ninhos; reutilização dos ninhos, e pragas e inimigos.

\section{RESULTADOS}

\section{Povoamento espontâneo das caixas racionais por} mamangavas

O povoamento espontâneo das caixas racionais aconteceu tanto em Fortaleza quanto em São Luís do Curú. Em ambos os casos, apenas abelhas da espécie $\boldsymbol{X}$. frontalis inspecionaram e colonizaram as caixas. A mamangava fêmea, em busca de local para nidificação, aproximava-se da caixa e começava a revoar ao seu redor examinando as condições antes de pousar.
A abordagem sempre ocorria próximo às cunhas de entrada dos quadros, demonstrando a atração que essas estruturas exercem sobre as mamangavas. Após revoá-las, a fêmea pousava próximo ou diretamente na abertura de uma delas e explorava o seu interior, podendo começar a escavar o ninho imediatamente ou após alguns minutos ou horas. Nesse caso, a fêmea saía da cunha de entrada e repetia seus vôos de inspeção naquela mesma cunha, e nas dos quadros vizinhos antes de decidir-se definitivamente por iniciar a escavação.

O povoamento foi observado em todas as caixas colocadas em Fortaleza e São Luís do Curú, atingindo uma média de 4,7 e 3,0 ninhos por caixa, respectivamente. Cada ninho foi construído em um quadro independente, não havendo, portanto, nenhum 
quadro povoado com mais de um ninho. Não houve desistência de ninhos, e todos os quadros nos quais observaram-se escavações apresentaram ninhos com crias em seu interior. Considerando o número de ninhos disponíveis para nidificação, o povoamento variou de 18,75\% em São Luís do Curú a 52,22\% em Fortaleza.

\section{Biologia reprodutiva das mamangavas nidificando na caixa racional}

O período médio de desenvolvimento de ovo a adulto das mamangavas produzidas na caixa racional foi observado em São Luís do Curú e durou cerca de 45 dias, sendo aproximadamente 5 dias como ovo, 15 dias como larva e 25 dias no estágio de pupa (Tabela 1). Os ninhos de Fortaleza produziram 21 machos e 26 fêmeas, apresentando uma relação macho/ fềmea de $0,82: 1,00$, em São Luís do Curú foram gerados 04 machos e 10 fêmeas, atingindo $0,40: 1,00$. Considerando as duas localidades, a média geral foi de $0,60: 1,00$.

O estudo da arquitetura dos ninhos construídos na caixa racional para mamangavas mostrou que eles são formados por um sistema de galerias que tem início na parte externa do ninho, com a porção já previamente escavada dentro da cunha de entrada. A partir do ponto em que a cavidade pré-escavada da cunha entra em contato com a tábua de madeira interna do quadro, a mamangava escava um curto túnel com inclinação entre 30 e $45^{\circ}$. Esse túnel, que se abre em uma câmara interna, é construído obedecendo à mesma direção e sentido da entrada da cunha. A partir da câmara interna, surgem as galerias com células horizontais em suas extremidades, nas quais a mamangava realiza sua postura e produz suas crias.

A primeira galeria comumente possui apenas duas ou três células, e a segunda normalmente é mais curta, embora possa conter duas células, e é construída na direção oposta à primeira. A segunda galeria também inicia-se a partir da câmara interna, a qual se torna maior com o aumento no número de galerias do ninho. Como o número de células por galeria é pequeno, o mesmo ninho pode apresentar uma terceira, e até uma quarta

Tabela 1 - Duração, em dias, do ciclo de desenvolvimento de ovo a adulto da mamangava Xylocopa frontalis na caixa racional.

\begin{tabular}{lcc}
\hline $\begin{array}{l}\text { Fase do desenvolvimento } \\
\text { de Xylocopa frontalis }\end{array}$ & $\mathrm{N}$ & $\begin{array}{c}\text { Dias (x } \pm \text { erro } \\
\text { padrão) }\end{array}$ \\
\hline Ovo & 15 & $4,84 \pm 0,10$ \\
Larva & 15 & $14,15 \pm 0,15$ \\
Pupa & 15 & $26,5 \pm 0,14$ \\
Ovo - Adulto (Total) & 15 & $45,58 \pm 0,26$ \\
\hline
\end{tabular}

galeria, construídos pela mesma fêmea. Essas galerias são feitas acima das anteriores, iniciando-se também na câmara central do ninho e seguindo o mesmo padrão anterior: a terceira no mesmo sentido da primeira e também comportando duas a três células e a quarta, acima da segunda com até duas células. Caso o ninho venha a ser reutilizado por uma ou mais filhas, ou alguma outra mamangava, esse padrão normalmente é obedecido, com as novas proprietárias escavando suas próprias galerias e células ou aumentando as galerias já existentes. As medidas médias das principais estruturas dos ninhos de mamangavas na caixa racional encontram-se na tabela 2.

Os dados coletados na caixa racional mostraram que as mamangavas $\boldsymbol{X}$. frontalis praticamente não enfrentaram problemas com pragas e inimigos. Por outro lado, a mortandade de crias no período de ovo a adulto foi de $17,6 \%$ e relacionou-se a problemas específicos da caixa racional. Essa mortandade ocorreu apenas durante a fase de larva, sendo $6,0 \%$ devido a danos causados ao lacre das células durante a manipulação dos quadros e 11,6\% a ataques de formigas, principalmente Camponotus sp., que construíram seus ninhos entre a lâmina de vidro e a tábua de madeira colocada como substrato de nidificação para as mamangavas. Cuidados na manipulação dos quadros e combate à Camponotus sp. podem reduzir a mortandade, consideravelmente.

Considerando as crias adultas, verificouse, em certas épocas do ano, a ocorrência de indivíduos com asas atrofiadas. Embora essa má formação não tenha impedido a sobrevivência da larva, ela faz com que o adulto morra quando ele tenta fazer seu primeiro vôo, pois não consegue mais retornar ao ninho. As causas desse fenômeno precisam ser melhor estudadas, pois aparentemente está relacionado com a falta de alimento no campo já que sempre ocorreu quando as floradas estavam em seu final.

Tabela 2 - Dimensões das principais estruturas dos ninhos de mamangavas (Xylocopa frontalis) nas caixas racionais em Fortaleza e São Luís do Curú - CE.

\begin{tabular}{lcc}
\hline Observação & $\mathrm{N}$ & $\mathrm{x} \pm$ erro padrão $(\mathrm{cm})$ \\
\hline Diâmetro da entrada & 8 & $2,50 \pm 0,00$ \\
Diâmetro da câmara interna & 8 & $2,51 \pm 0,01$ \\
Diâmetro da galeria & 8 & $2,14 \pm 0,02$ \\
Diâmetro da célula & 8 & $2,16 \pm 0,02$ \\
Comprimento da galeria & 8 & $10,81 \pm 0,77$ \\
Número de galerias/ninho & 8 & $1,87 \pm 0,16$ \\
Número de células/galeria & 8 & $2,62 \pm 0,24$ \\
\hline
\end{tabular}




\section{DISCUSSÃO}

O modelo de ninho racional testado foi capaz de atrair as mamangavas, levá-las à nidificação e à produção de crias com sucesso. Quase todos os parâmetros avaliados nesse estudo, como a forma de abordagem, taxa de colonização, tempo de desenvolvimento das crias, relação macho-fêmea produzida e reutilização dos ninhos apresentaram resultados semelhantes ao descrito na literatura para nidificação em condições silvestres ou em ninhosarmadilhas (CAMILLO, 1979; CAMILLO \& GARÓFALO, 1982; CAMILLO et. al., 1986; O'TOOLE e RAW 1991; SIHAG, 1993a,b; CAMILLO, 1998).

Apenas no que se refere à arquitetura dos ninhos e pragas e doenças foram observadas algumas diferenças entre a nidificação das mamangavas nos ninhos racionais e na natureza. No caso da arquitetura dos ninhos, embora ela seja parecida com a dos ninhos silvestres, e corresponda em parte ao descrito por CAMILLO \& GARÓFALO (1982) para ninhos de $\boldsymbol{X}$. frontalis $\mathrm{X}$.grisescens, uma diferença marcante residiu no fato de que os ninhos selvagens são quase sempre construídos na vertical e, quando o substrato permite, apresentam arquitetura tridimensional (CAMILLO, 1979). Mesmo assim, os ninhos da caixa racional, predominantemente horizontais e construídos em um único plano devido às limitações impostas pela tábua de madeira e as lâminas de vidro, não fogem a situações vividas pelas abelhas na natureza na qual se pode encontrar com certa freqüência ninhos horizontais e bidimensionais em função do substrato em que a mamangava nidifica.

No que se refere a doenças e inimigos, apesar da literatura (HURD, 1978) relatar a existência de parasitismo em larvas de $\boldsymbol{X}$. frontalis e $\boldsymbol{X}$. grisescens pelo besouro Cissites maculata, nenhum caso foi observado. Já a mortandade das larvas, esta pode ser reduzida consideravelmente com maiores cuidados na manipulação dos quadros e combate à Camponotus sp..

\section{CONCLUSÃO}

Conclui-se, portanto, que os hábitos de nidificação e reprodução das mamangavas no modelo testado são semelhantes ao observado na natureza, podendo o mesmo ser usado com sucesso para o criatório de mamangavas. Porém, há a necessidade de avaliar se o seu uso em áreas agrícolas contribui para aumento de produtividade das culturas, uma vez que o maior interesse no criatório de mamangavas reside na utilização dessas abelhas como agente polinizador.

\section{REFERÊNCIASBILIOGRÁFICAS}

CAMILlO, E. Aspectos ecológicos e evolutivos de abelhas do gênero Xylocopa (Hymenoptera, Anthophoridae) 1979. 173f. Dissertação (Mestrado em Ecologia e Recursos Naturais) - Universidade Federal de São Carlos.

CAMILLO, E. Estudos sobre o incremento dos polinizadores (Hymenoptera, Apidae, Xylocopini) do maracujá amarelo (Passiflora edulis f. flavicarpa Deg.). In: CONGRESSO BRASILEIRO DE APICULTURA, 12., 1998, Salvador. Anais... Salvador : Confederação Brasileira de Apicultura, 1998. p.134-136.

CAMILlO, E. Polinização do maracujazeiro: mamangavas $\mathrm{x}$ africanizadas. In: CONGRESSO BRASILEIRO DE APICULTURA, 13., 2000, Florianópolis. Anais... Florianópolis : Confederação Brasileira de Apicultura, 2000. CD-Rom.

CAMILlO, E.; GARÓFALO, C.A. On the bionomics of Xylocopa frontalis (Olivier) and Xylocopa grisescens (Lepeletier) in southern Brazil. I. Nest construction and biological cycle. Revista Brasileira de Biologia, Rio de Janeiro, v.42, p.571582, 1982

CAMILlO, E.; GARÓFALO, C.A.; MUCCILlO, G. On the bionomics of Xylocopa suspecta (Moure) in southern Brazil: nest construction and biological cycle (Hymenoptera, Anthophoridae). Revista Brasileira de Biologia, v.46, p.383-393, 1986 .

CORBET, S.A.; WILLMER, P.G. Pollination of the yellow passionfruit: nectar, pollen and carpenter bees. Journal of Agricultural Science, Cambridge, v.95, p.655-666, 1980.

FREITAS, B.M.; OLIVEIRA FILHO J. H. Criação racional de mamangavas para polinização em áreas agrícolas. Fortaleza : Banco do Nordeste, 2001. 96p.

HURD, P.D. An annoted catalog of the carpenter bees (genus Xylocopa Latreille) of the western hemisphere (Hymenoptera, Anthophoridae). Washington D.C.: Smithsonian Institution, 1978. 106p.

MARDAN, M. Varied pollinators for Southeast Asian crops. In: ROUBIK, D.W. (Ed). Pollination of cultivated plants in the tropics. Roma : FAO, 1995. p.142-149. (FAO Agricultural Services Bulletin 118).

MARDAN, M.; RAHMAN, H.A.; WONG, M.L. A new technique for mass rearing carpenter bees on dry wood logs. In: INTERNATIONAL CONFERENCE ON APICULTURE IN TROPICAL CLIMATES, 5., 1992, Port of Spain. Proceedings... Cardiff : IBRA, 1994. p.149-155.

RUGGIERO, C. Situação da cultura do maracujazeiro no Brasil. Informe Agropecuário, Belo Horizonte, v.21, n.206, p.5-9, set/out, 2000.

SIHAG, R.C. Behaviour and ecology of the subtropical carpenter bee, Xylocopa fenestrata F.7. Nest preferences and response to nest translocation. Journal of Apicultural Research, Cardiff, v.32, n.2, p.102-108, 1993a.

SIHAG, R.C. Behaviour and ecology of the subtropical carpenter bee, Xylocopa fenestrata F.8. Life cycle, seasonal mortality, parasites and sex ratio. Journal of Apicultural Research, Cardiff, v.32, n.2, p.109-114, 1993b. 